\title{
The evaluation of opinions of the parents of children with cerebral palsy on exercise therapy applied in Special Education and Rehabilitation Centers in rural areas
}

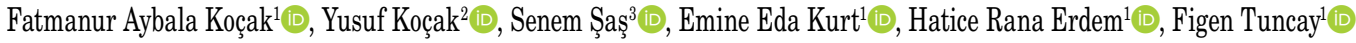 \\ ${ }^{1}$ Department of Physical Medicine and Rehabilitation, Medicine Faculty of Kırşehir Ahi Evran University, Kırşehir, Turkey \\ ${ }^{2}$ Department of Neurology, Medicine Faculty of Kırşehir Ahi Evran University, Kırşehir, Turkey \\ ${ }^{3}$ Department of Physical Medicine and Rehabilitation, Kırşehir Ahi Evran University, Training and Research Hospital, Kırşehir, Turkey
}

Received: March 13, 2018 Accepted: July 30, 2018 Published online: November 02, 2018

Cerebral palsy $(\mathrm{CP})$ is one of the most common causes of neurological impairment in childhood. ${ }^{[1]}$ Many children who are followed with a diagnosis of $\mathrm{CP}$ are unable to attend to an ordinary school due to physical or mental disability, and they need special education. Special education is provided by speciallytrained personnel with training programs, equipment, and methods based on the qualifications and developmental characteristics of individuals who require different education from general education and also to meet their social needs. Special education in Turkey is given by the Special Education and Rehabilitation Center Schools (SERCs), which are affiliated with the Republic of Turkey, Ministry of Education. ${ }^{[2]}$ Special education teachers, school counsellors, psychologists, social workers, and physiotherapists work in these centers. Exercise therapy is provided by physiotherapists in SERCs.

The aim of this study was to evaluate the opinions of the parents of children with CP on exercise therapy provided in the SERCs in rural areas. The records of the Physical Medicine and Rehabilitation (PMR) outpatient clinics of Republic of Turkey, Ministry of Health Ahi Evran University Training and Research Hospital were examined for the past three years (2015-2017). Demographic data were recorded from the files of the patients with $\mathrm{CP}$ and their parents were contacted by telephone to conduct a survey, and a total of $9.8 \%$ parents were unable to be reached. The total number of patients was 278 (166 males and 112 females) and 184 were aged under 18 years (111 males and 73 females). The mean age of all patients was $15.6 \pm 13.8$ years, and the mean age of patients aged under 18 years was $7.2 \pm 5.3$ years. Treatment was given in the PMR clinics of the hospital to $37.4 \%$ of all patients and $44.9 \%$ of patients aged under 18 years. A total of $10.9 \%$ of the parents were unwilling for PMR in the hospital setting, while $37.8 \%$ were willing for PMR, but refused due to social reasons. Just over half (53.2\%) of the parents of the patients who did not receive the PMR in the hospital reported that exercise therapy applied in the SERCs was adequate; however, $61.4 \%$ of the parents were unaware that the SERCs do not employ PMR specialists (i.e., physiatrists) in their centers. The main reasons for preferring SERCs rather than hospital are listed in Table 1.

According to our results, the most important reason for parents choosing SERCs was their inability to do exercise at home which can be attributed to fatigue. Similarly, in a previous study, mothers of children with $\mathrm{CP}$ reported increased levels of fatigue with respect to the intensity of fatigue, duration of fatigue, and interference with quality of life. ${ }^{[3]}$ The second most important reason was that the parents considered SERCs as social activity centers.

Corresponding author: Fatmanur Aybala Koçak, MD. Kırşehir Ahi Evran Üniversitesi Tip Fakültesi, Fiziksel Tıp ve Rehabilitasyon Anabilim Dalı, 40100 Kırşehir, Turkey. 
Table 1. Reasons of parents for choosing to receive exercise therapy in the SERCs for their children

\begin{tabular}{l}
\hline Reason \\
\hline I/we cannot do appropriate exercise therapy at home. In this case, my child's joints become more stiff. \\
My child attends to social activities in a SERC, there are friends there who resemble her/him. \\
Special Education and Rehabilitation Center School has the possibility to transport my child with the bus, the hospital does not \\
have such a possibility. \\
There are staff in the bus who help my children to take away and I do not have to go with her/him. Thus, I could do my own \\
work (e.g., shopping, visiting friends). \\
My child cannot receive physical therapy after a particular session in the hospital, but it can be done at a SERC continuously \\
through the year. \\
I did not know that physical therapy can be applied at the hospital, so the pediatrician told us to attend SERC.
\end{tabular}

SERC: Special Education and Rehabilitation Center School.

In conclusion, the results of our study showed that more than half of the parents did not choose a PMR program in the hospital setting in rural areas. The social rights of disabled children and their parents need to be increased. Coordination with the Ministry of Health is essential for the planning, management, and supervision of exercise therapy in SERCs.

\section{Declaration of conflicting interests}

The authors declared no conflicts of interest with respect to the authorship and/or publication of this article.

\section{Funding}

The authors received no financial support for the research and/or authorship of this article.

\section{REFERENCES}

1. Serdaroğlu A, Cansu A, Ozkan S, Tezcan S. Prevalence of cerebral palsy in Turkish children between the ages of 2 and 16 years. Dev Med Child Neurol 2006;48:413-6.

2. Milli Eğitim Bakanlığı Özel Kurumlar Yönetmeliği. Resmi Gazete, Tarih: 18.05.2012, Say1: 28296.

3. Garip Y, Ozel S, Tuncer OB, Kilinc G, Seckin F, Arasil T. Fatigue in the mothers of children with cerebral palsy. Disabil Rehabil 2017;39:757-62. 